\title{
Thermal Simulating Analysis of PCU on Satellite
}

\author{
Fang Fang Sun ${ }^{1, a}$, Peng $\mathrm{Li}^{2, \mathrm{~b}}$ and Cai Ping Liang ${ }^{1, \mathrm{C}}$ \\ ${ }^{1}$ Mechanics and Electronic Engineering Faculty, Shanghai Second Polytechnic University, Shanghai, \\ China \\ ${ }^{2}$ Continental Automotive Changchun Co., Ltd. Shanghai Branch, Shanghai, China

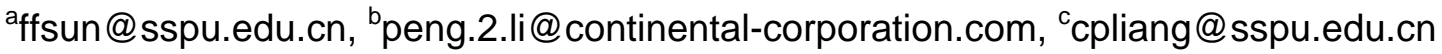

Keywords: Power control unit, Thermal analysis, Flotherm software, Temperature distribution

\begin{abstract}
Power control unit (PCU) is the controlling center of space satellite power system; it controls the energy that output from solar array and batteries and the power balance of the whole satellite. The circuit board, components and power tube in PCU is working in a long time and in high power situation, so reasonable thermal design is crucial for PCU. Thermal simulating analysis of PCU is done in this paper. The whole thermal model of PCU is established and temperature distribution is calculated by electronic equipment thermal analysis software Flotherm, according to system input conditions and related requirements.
\end{abstract}

\section{Introduction}

Power control unit (PCU) [1] is an important component of sub-power system of satellite, and was equipped with batteries in service module board of satellite [2]. During the running of satellite on-orbit, it absorbs the heat of sunlight, sunlight reflection, and radiation of planet emission, etc. This thermal energy generates heat radiation to PCU via satellite deck [3-4]. PCU transforms heat by radiation and conduction with others equipment on satellite deck. And PCU generates heat from components of print circuit board, power dissipation of inductance and power tube, therefore reasonable control method has to be adopted to reach thermal equilibrium.

PCU uses modular design, it consist of discharge module 1, discharge module 2, capacitor module, MEA module, BEA module, shunt module, shunt charging module1, shunt charging module 2, shunt charging module 3 , ground control module, TM/TC module 1 , TM/TC module 2 , and 4 draw rods. The shell material of PCU is $2 \mathrm{Al} 2$ duralumin. There are 19 PCB boards in 12 PCU modules, and the material of PCB is epoxy glass with double-sides copper foil board. Discharge module 1 and 2 have 24 high power components respectively, capacitor module has no high power component, MEA and BEA have 3 high power components, shunt module has 20 high power components, shunt charge module 1,2 and 3 have 28 high power components, ground control module have 4 high power components, TM/TC module 1 and 2 have no high power components.

\section{PCU Thermal Conditions Analysis}

Thermal Input Conditions. The working temperature range of PCU is $-15^{\circ} \mathrm{C} \sim 45^{\circ} \mathrm{C}$, while test temperature range is $-35^{\circ} \mathrm{C} 70^{\circ} \mathrm{C}$, extreme temperature point is $-35^{\circ} \mathrm{C},-15^{\circ} \mathrm{C}, 50^{\circ} \mathrm{C}, 70^{\circ} \mathrm{C}$. The working cycle of PCU is $95 \mathrm{~min}$, in which $60 \mathrm{~min}$ is in the light and working power is $220 \mathrm{~W}$, the left is in the shadow time and working power is $200 \mathrm{~W}$. The temperature distribution is calculated in this paper while the environment temperature is $-15^{\circ} \mathrm{C}$. Satellite will experience sunlight period and shadow period according to the different running mode. Sunlight period time is divided into sunlight charging mode and sunlight shunt mode. When satellite experiences sunlight period time MEA module, shunt module, shunt charging module1, shunt charging module 2, shunt charging module 3 and ground control module runs. While satellite experiences shadow period time discharge module 1 , discharge module 2, MEA module and ground control module runs. 
Thermal Design Conditions. High power devices 2N7225、2N7236、1212CGQ150、15CGQ100、 CW117 is installed in bottom or side plate by $\Phi 3$ screw. MHF+2812DF are installed in bottom or side plate as well by two $\Phi 3$ positioning screws, so their thermal is radiated by metal structure directly. These devices are used in metal shell packaging and installation surface are coated with thermal conductive grease. Heat concentrates in shunt module, shunt charging module1, shunt charging module 2, shunt charging module 3 when PCU works in sunlight. While heat concentrates in discharging module 1 and discharging module 2 when PCU works in shadow. The parameter of high power parts is shown in Table 1.

Table 1 Rated parameters of high power parts

\begin{tabular}{|l|l|l|l|l|l|l|}
\hline No. & Model & Package & Size $[\mathrm{mm}]$ & $\begin{array}{l}\text { Shell resistance } \\
{\left[{ }^{\circ} \mathrm{C} / \mathrm{W}\right]}\end{array}$ & $\begin{array}{l}\text { Derating } \\
\left.\text { temperature }{ }^{\circ} \mathrm{C}\right]\end{array}$ & Remarks \\
\hline 1 & $2 \mathrm{~N} 7225$ & TO254 & $20.3 \times 13.8 \times 6.6$ & 0.83 & 85 & 85 \\
\hline 2 & $2 \mathrm{~N} 7236$ & TO254 & $20.3 \times 13.8 \times 6.6$ & 1.0 & 90 & \\
\hline 3 & 12 CGQ150 & TO254 & $20.3 \times 13.8 \times 6.6$ & 0.83 & 90 & \\
\hline 4 & 15 CGQ100 & TO254 & $20.3 \times 13.8 \times 6.6$ & 0.83 & 85 & \\
\hline 5 & MHF+2812DF & $/$ & $50.9 \times 28.7 \times 8.3$ & $/$ & 80 & \\
\hline 6 & CW117 & TO204AA & $/$ & $/$ & & \\
\hline
\end{tabular}

\section{Establish Thermal Simulation Model}

Simplified Model Assumptions. Because of the complexity of PCU, it is necessary to simplify the model before simulation. [5]

1) Constant temperature boundary condition is used in calculation, namely that external temperature of shell is fixed ,therefore ribs, threaded hole, chamfer and fillet details of modal is removed.

2) The structure and components that have irregular shape are simplified according to the equivalent radiation area.

3) The components that have high power are modeled according to their actual size and position.

4) The components that installed on the aluminum plate directly are treated as insulating and filled with thermal grease.

Simulation Model. PCU is modeled according to its actual size, its material is Duralumin. Thermal conductivity is $200.96 \mathrm{~W} /(\mathrm{m} \cdot \mathrm{K})$, density is $2800 \mathrm{~kg} / \mathrm{m}^{3}$, specific heat is $1.0465 \mathrm{~kJ} /(\mathrm{kg} \cdot \mathrm{K})$. PCB board is FR4, that was generated by insulator and copper after heating and pressurizing. Then a new material is generated according to copper thickness and copper coverage (copper area of coverage percentage of PCB board area), which conductivity is 0.3 $\mathrm{W} /(\mathrm{m} \cdot \mathrm{K})$, density is $1200 \mathrm{~kg} / \mathrm{m}^{3}$, specific heat is $880 \mathrm{~kJ} /(\mathrm{kg} \cdot \mathrm{K})$. Components are modeled according to their sizes and relative positions of PCB board, base plate and side plate. And all packing material of components is metal. When current passes through the PCB, there is a part of the energy of components dissipated as heat, which is called heat consumption. In order to simplify the model, the heat consumption of all high power components are thinks as equivalent to power consumption. Thermal analysis of simplified model is shown in figure 1.

Initial conditions of the simulation

1) Enviorment temperature: $-15^{\circ} \mathrm{C}$

2) Model type: 3D model

3)Unit: Millmeter

4) Model method:steady modeling

5) Turbulence model: automatic turbulence

6) Calculation type: flow and heat transfer 
7) Heat transfer coefficient: $5 \mathrm{~W} /\left(\mathrm{m}^{2} \cdot \mathrm{K}\right)$

8) Gravity direction: -Y

9) Relative pressure:(Pa): 0

10) Solving iterations: 500

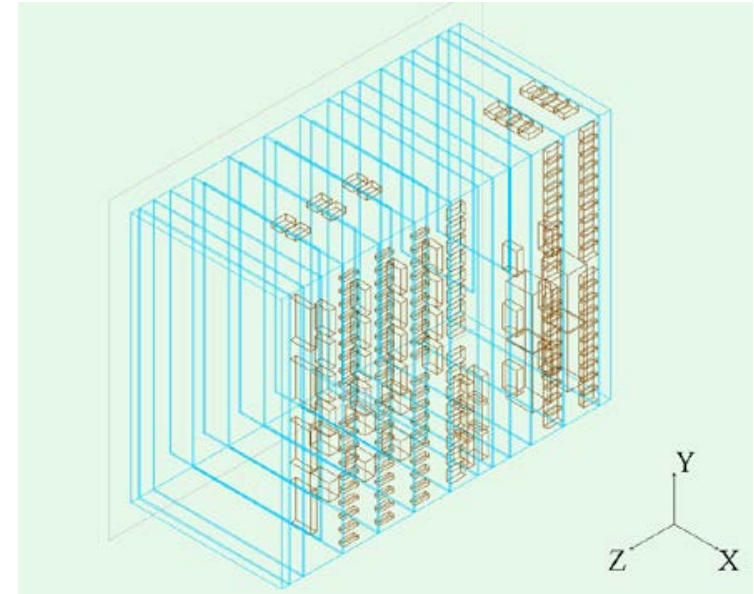

Fig 1. Thermal analysis model of PCU

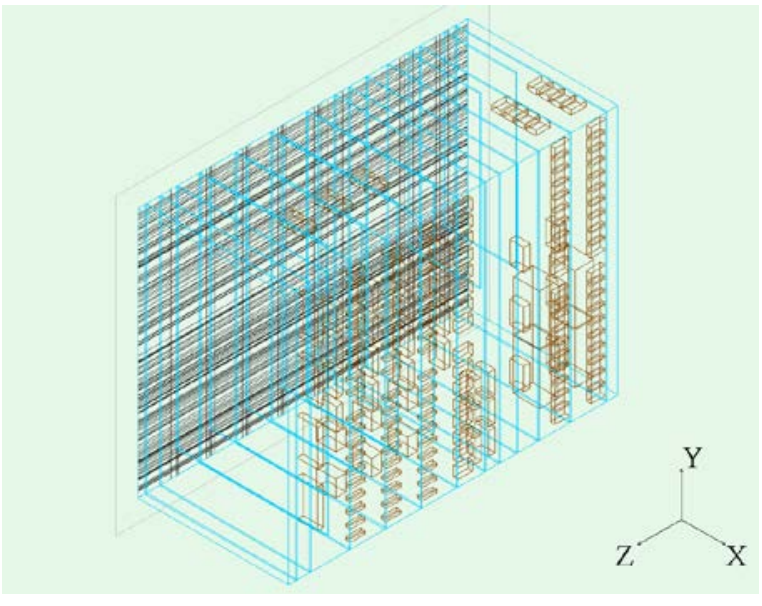

Fig 2. Meshes divided of the simulation model

Meshing simulation model. Generally, the more mesh is divided, the higher precision of calculation, but too much mesh will lead to too long computing time, and computing precision does not be improved obviously. Because of the relatively high heat components in the system, which makes heat distribution is uneven in domain, the fine local meshes are applied to high power components, while the rough meshes are applied to other components. The overall meshes distribution of system are shown in figure 2. The meshes number is 272580 .

\section{Simulation Results and Analysis}

There are many working conditions of PCU; one of them is selected in this paper. The environment temperature is $-15^{\circ} \mathrm{C}$, discharging module 1 and discharging module 2 works in the shadow, Shunt modules works in the entire split status, charging and discharging module works in full charge and full shunt status. Temperature distribution of PCU is shown in Fig 3-Fig 5, and the non zero power element temperature value is shown in Table 2.

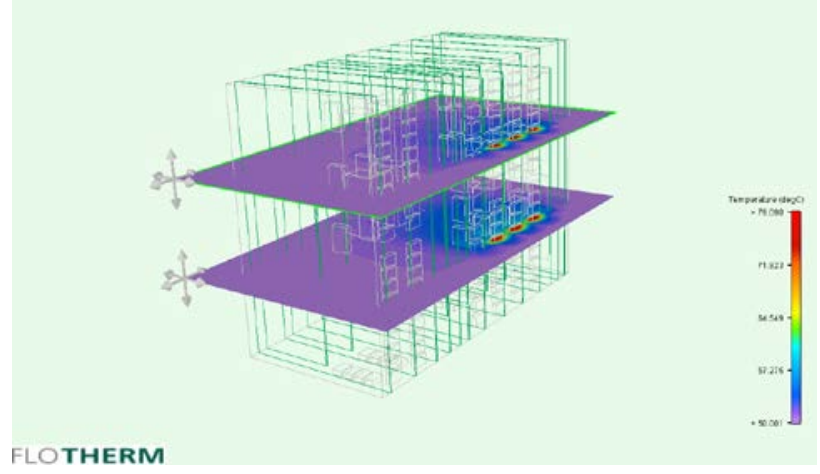

Fig 3. Temperature distribution of $\mathrm{X}$ direction

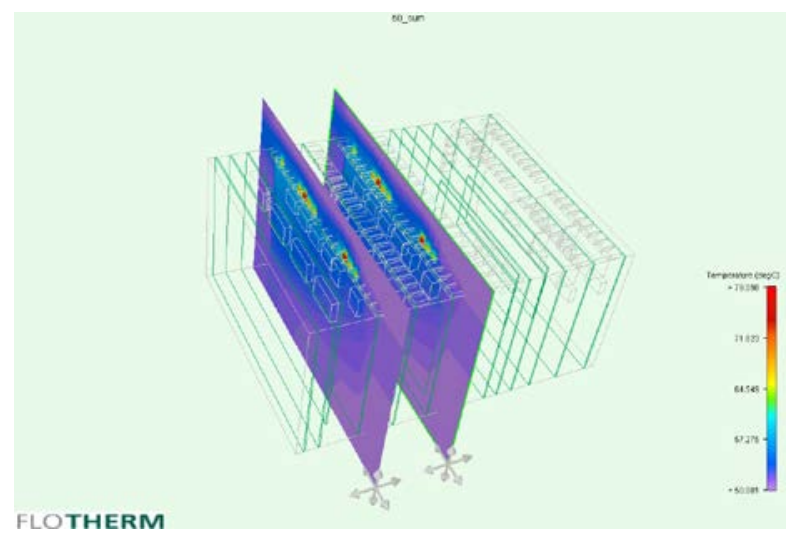

Fig 4. Temperature distribution of Y direction 


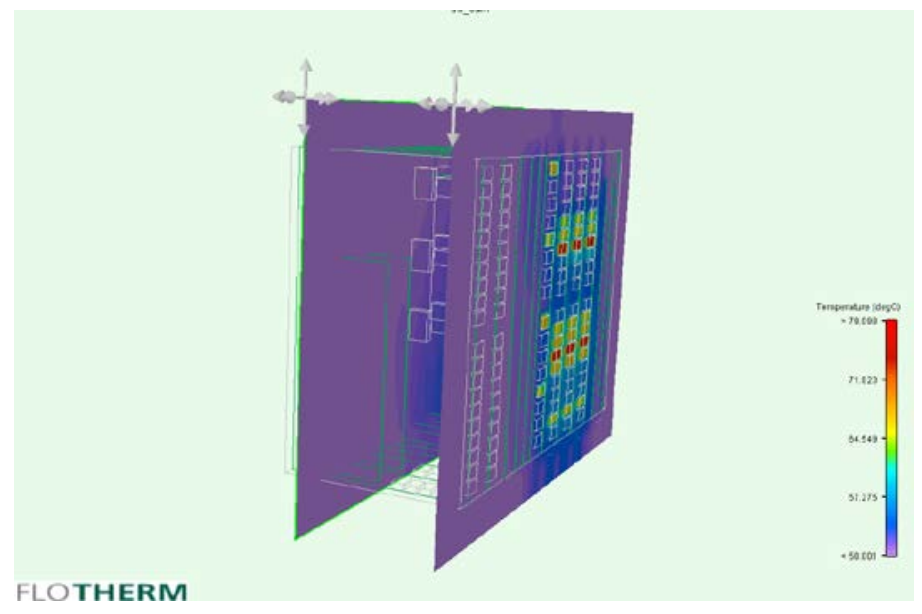

Fig 5. Temperature distribution of $\mathrm{Z}$ direction

Table 2. Temperature of all high power components

\begin{tabular}{|c|c|c|c|}
\hline Components type & $\begin{array}{c}\text { Heat } \\
\text { consumption } \\
{[\mathrm{W}]}\end{array}$ & Shell temperature $\left[{ }^{\circ} \mathrm{C}\right]$ & Junction temperature $\left({ }^{\circ} \mathrm{C}\right)$ \\
\hline Q11 2N7225 & 3.97 & 65.151 & 68.4 \\
\hline Q21 2N7225 & 3.97 & 65.802 & 69.1 \\
\hline Q31 2N7225 & 3.97 & 64.724 & 68 \\
\hline Q41 2N7225 & 3.97 & 65.061 & 68.3 \\
\hline Q12 2N7236 & 7.9 & 76.549 & 69.4 \\
\hline D24 12CGQ150 & 4 & 66.11 & 70.8 \\
\hline D25 12CGQ150 & 4 & 67.575 & $/$ \\
\hline N2 MHF+2812DF & 2 & 56.05 & \\
\hline
\end{tabular}

Through the thermal analysis of internal components of PCU, the thermal stress and temperature distribution of main components are obtained. The junction temperature of all components can satisfy the I rerating requirements.

\section{Acknowledgements}

This work was financially supported by Innovation Program of Shanghai Municipal Education Commission (No.10YZ205), and Shanghai Municipal Education Commission Fund (No.EGD09011).

\section{References}

[1] Shun Luo: Guangdong Technology, No 221, p.72-73, in Chinese

[2] E. E. N. Macau, L. F. Ramos Turci and T. Yoneyama: The European Physical Journal-Special Topics, 2008, Vol 165, p.221-228

[3] Zhenkun Guan: Chinese Journal of Power Sources. Vol.32 No.11, p 780-783, in Chinese

[4] Hui Ma: Chinese Journal of Power Sources. Vol.32 No.11, p 776-779, in Chinese

[5] Shaoran Liu and Zhongxu Xu: Computer Simulation. 2011.p 165-169, in Chinese 